\title{
FLIGHT TEST EXPERIENCE WITH AN ELECTROMECHANICAL ACTUATOR ON THE F-18 SYSTEMS RESEARCH AIRCRAFT
}

\author{
Stephen C. Jensen, NASA Dryden Flight Research Center, Edwards, CA \\ Gavin D. Jenney, PhD, PE; Bruce Raymond, PE; Dynamic Controls, Inc, Dayton, OH \\ David Dawson, USAF Wright Laboratory, Wright-Patterson AFB, OH
}

\begin{abstract}
Development of reliable power-by-wire actuation systems for both aeronautical and space applications has been sought recently to eliminate hydraulic systems from aircraft and spacecraft and thus improve safety, efficiency, reliability, and maintainability. The Electrically Powered Actuation Design (EPAD) program was a joint effort between the Air Force, Navy, and NASA to develop and fly a series of actuators validating power-by-wire actuation technology on a primary flight control surface of a tactical aircraft. To achieve this goal, each of the EPAD actuators was installed in place of the standard hydraulic actuator on the left aileron of the NASA F/A-18B Systems Research Aircraft (SRA) and flown throughout the SRA flight envelope. Numerous parameters were recorded, and overall actuator performance was compared with the performance of the standard hydraulic actuator on the opposite wing. This paper discusses the integration and testing of the EPAD electromechanical actuator (EMA) on the SRA. The architecture of the EMA system is discussed, as well as its integration with the F/A-18 Flight Control System. The flight test program is described, and actuator performance is shown to be very close to that of the standard hydraulic actuator it replaced. Lessons learned during this program are presented and discussed, as well as suggestions for future research.
\end{abstract}

\section{Introduction}

Power-by-wire (PBW) actuation is the next major breakthrough in aircraft control. Just as the fly-by-wire flight control system eliminated the need for mechanical interfaces, power-by-wire actuators eliminate the need for central hydraulic systems. Control power comes directly from the aircraft electrical system. This has several advantages. Central hydraulic systems are complicated and difficult to maintain. Removing these systems would greatly reduce the amount of support equipment and personnel required to maintain and operate current air and space vehicles. In addition, $\mathrm{PBW}$ actuators have the potential to be more efficient than their hydraulic counterparts. A central hydraulic system must generate and sustain significant hydraulic pressure (3,000 to 6,000 pounds per square inch) at all times, regardless of demand. PBW actuators only use electrical power when needed. Finally, PBW actuation systems can be made far more fault tolerant than those depending on a central hydraulic supply. Once a hydraulic line is compromised, it usually leads to the loss of that entire hydraulic circuit. As a result, multiple hydraulic circuits are required to maintain some level of redundancy. With a PBW system, a failed actuator can simply be switched off, isolating the problem to a single surface.

\section{Types of PBW Actuators}

There are several different types of PBW actuators, including electrohydrostatic actuators (EHA) and electromechanical actuators (EMA). EHAs use a reversible, electrically driven pumpmotor to directly pump self-contained hydraulic fluid to a piston. This drives the ram in the same fashion as a standard hydraulic actuator (Figure 1(a)). An EMA has no internal hydraulic fluid, instead using electric motors to directly drive the ram through a mechanical gearbox (Figure 1(b)). Compared to an EHA, the EMA has certain advantages. It is lighter, smaller, and less complex than an equivalent EHA because of the absence of an internal hydraulic system. Since there is no hydraulic fluid in the load path, the EMA tends to be stiffer than an equivalent EHA. The EMA tends to be more efficient because there are no windage losses or pump 
inefficiencies. Finally, since there is no leak potential with an EMA, it is better suited to longterm storage or space applications.

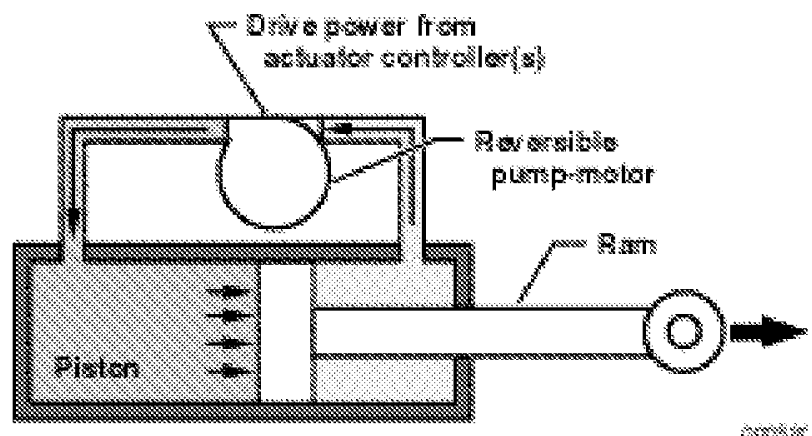

(a) Electrohydrostatic Actuator (EHA).

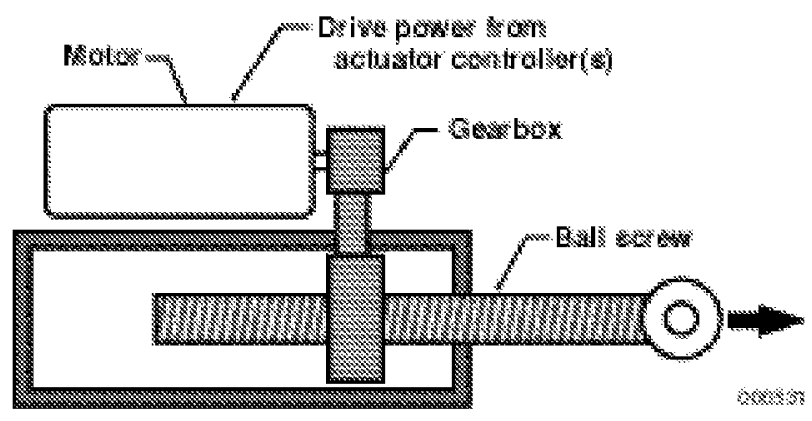

(b) Electromechanical Actuator (EMA).

Figure 1. Examples of power-by-wire actuators.

\section{Electrically Powered Actuation Design Program Goals}

The Electrically Powered Actuation Design validation program (EPAD) was managed by the Air Force Research Laboratory, Control Systems Development \& Applications Branch, WrightPatterson Air Force Base, Ohio, and was a joint partnership between the Air Force, Navy and NASA. The objective of the EPAD program was to establish the credibility of electric actuation as the method of control for a primary control surface on a tactical aircraft. The EPAD program consisted of the design, development, and flight test of three aileron actuators on the NASA F/A-18B Systems Research Aircraft (SRA) [1]. The first actuator was the Smart Actuator, a hydraulic actuator with loop closure and failure detection performed locally at the actuator instead of in the F-18 flight control computers (FCC) as would normally be the case [2].
Communications to the Smart Actuator were by fiber optics. The second actuator was an EHA, with an external controller [3]. The third and final actuator was an EMA, the subject of this paper. The flight test objectives of the EPAD program were to measure actuator performance under actual flight conditions, and subject the actuator to combined surface loads (inertial, aerodynamic, and aeroelastic) and environments (noise, temperature, vibration, and electromagnetic interference (EMI)). The actuator was to be subjected to a series of realistic maneuvers including rapid flight changes, trim changes, and real flight dynamics.

Note that use of trade names or names of manufacturers in this document does not constitute an official endorsement of such products or manufacturers, either expressed or implied, by the National Aeronautics and Space Administration.

\section{Acronyms and Symbols}

\begin{tabular}{|c|c|}
\hline $\mathrm{Bdc}$ & brushless dc \\
\hline BIT & built-in-test \\
\hline $\mathrm{dB}$ & decibels \\
\hline EHA & electrohydrostatic actuator \\
\hline EMA & electromechanical actuator \\
\hline EMI & electromagnetic interference \\
\hline EPAD & $\begin{array}{l}\text { Electrically Powered Actuator } \\
\text { Design validation program }\end{array}$ \\
\hline FBW & fly-by-wire \\
\hline FCC & flight control computer \\
\hline$g$ & acceleration of gravity \\
\hline IBIT & initiated BIT \\
\hline IBOX & interface box \\
\hline $\mathrm{MCT}$ & $\begin{array}{l}\text { MOS-controlled thyristor }(\mathrm{MOS}= \\
\text { metal oxide semiconductor) }\end{array}$ \\
\hline PBIT & periodic BIT \\
\hline PBW & power-by-wire \\
\hline PCME & $\begin{array}{l}\text { power, control, and monitor } \\
\text { electronics }\end{array}$ \\
\hline PCU & power conversion unit \\
\hline$\overline{\mathrm{q}}$ & dynamic pressure, $1 \mathrm{~b} / \mathrm{ft}^{2}$ \\
\hline
\end{tabular}




$\begin{array}{ll}\text { SRA } & \text { Systems Research Aircraft } \\ \text { V ac } & \text { Volts alternating current } \\ \text { V dc } & \text { Volts direct current }\end{array}$

\section{EMA System Description}

\section{Standard F/A-18 Aileron Actuator}

The standard F/A-18 aileron actuators are dual-redundant hydromechanical servomechanisms. The F/A-18 flight control system is divided into four identical channels, with each aileron being driven by two separate channels. The system can withstand one electrical failure and one hydraulic failure and still function. If either two hydraulic or two electrical failures are detected, the system will revert to a "trail damped" mode, fairing into the airstream with enough dynamic stiffness to prevent flutter.

The ailerons on the F/A-18 are really flaperons, being used for both roll control and as flaps (Figure 2). If an actuator failure occurs with flaps down, the aircraft flight control logic will slowly bring the opposite flaperon up to maintain aircraft symmetry while the failed surface is blown to a faired position.

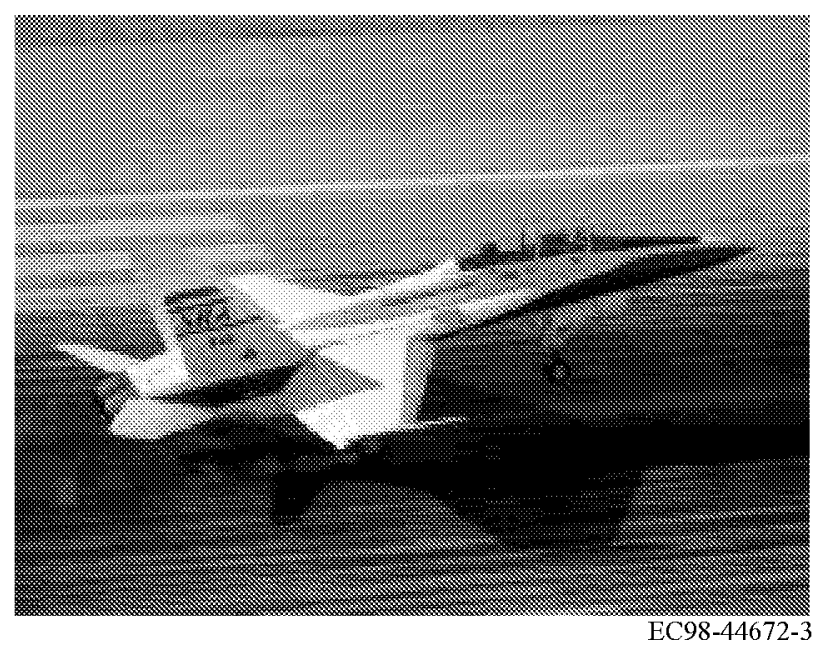

Figure 2. F/A-18B Systems Research Aircraft, showing ailerons in flap configuration.

\section{The EPAD EMA System}

\section{Architecture Overview}

The EPAD EMA system was designed to be a simplex replacement for the standard F/A-18 actuator that could be implemented without modification to the standard aircraft flight control system (Figure 3). All loop closure and failure detection occurs between the actuator and the power control and monitor electronics (PCME) unit located in the left wing. Two interface boxes (IBOXs) were required to both satisfy the loop closure and failure detection requirements of the aircraft FCCs and, at the same time, convert the rate commands generated by the FCCs into a position command usable by the actuator. A power conversion unit (PCU) was installed to rectify the 3-phase, $115 \mathrm{~V}$ ac aircraft supply into the $\pm 135 \mathrm{~V}$ dc ( $270 \mathrm{~V}$ dc differential) power required by the actuator. The existing aircraft instrumentation system acquired data from the IBOXs, the PCU, and additional aircraft sensors and telemetered it to the ground for real time monitoring and recording. Location of the various components on the aircraft is shown in Figure 4.

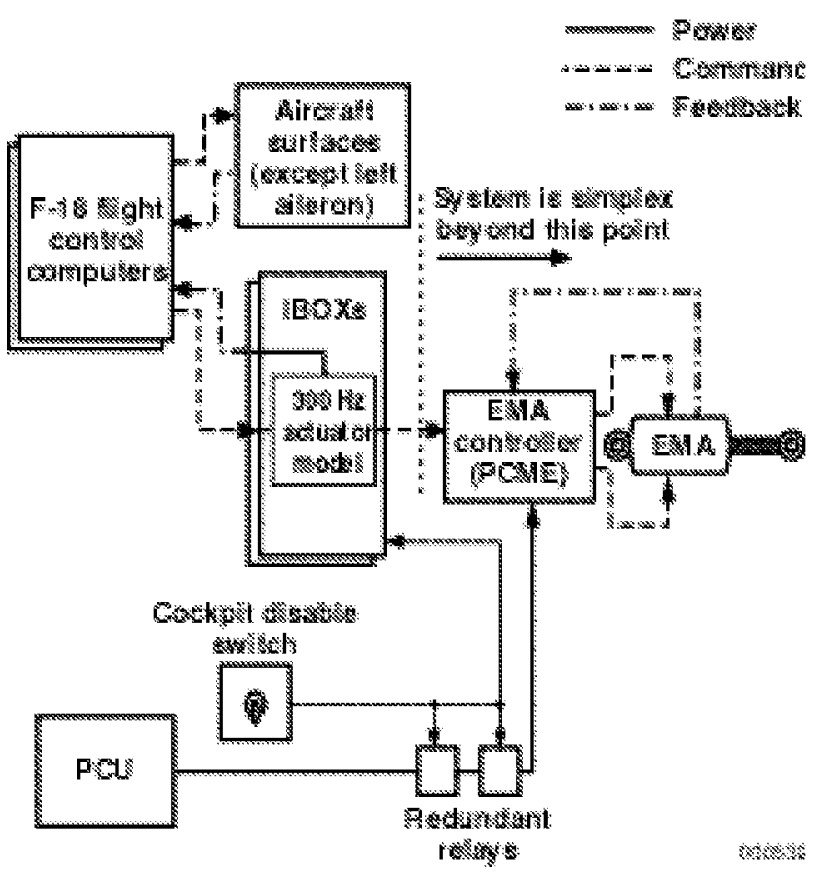

Figure 3. EPAD EMA system layout. 


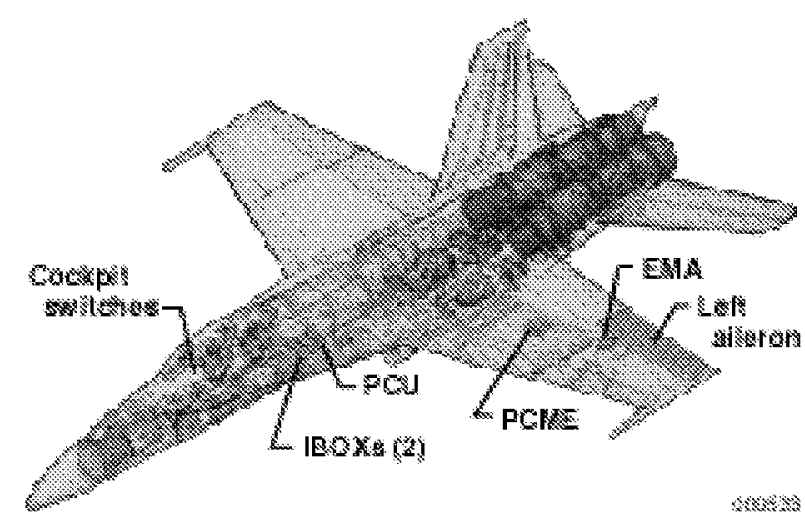

Figure 4. EPAD EMA hardware locations.

\section{Electromechanical Actuator (EMA)}

The EMA was designed and built by MPC Products (Skokie, Illinois). This actuator was designed to meet the same performance specifications as the standard F/A-18 hydraulic aileron actuator. The EMA consists of two 3-phase brushless dc (Bdc) motors driving a single ball screw through a velocity-summing differential. Mechanical stroke was 4.125 in. and maximum load was $13,200 \mathrm{lb}$. The actuator weighed approximately $26 \mathrm{lb}$, and was rated at approximately 5 horsepower maximum output. The production actuator has the same maximum load capability, and weighs approximately $17 \mathrm{lb}$. Maximum current draw for the EMA was 30 amperes (A) at $270 \mathrm{~V} \mathrm{dc}$, with a potential 70 A transient peak. An antirotation device was incorporated inside the actuator to prevent the ball screw from turning. The actuator is pictured in Figure 5.

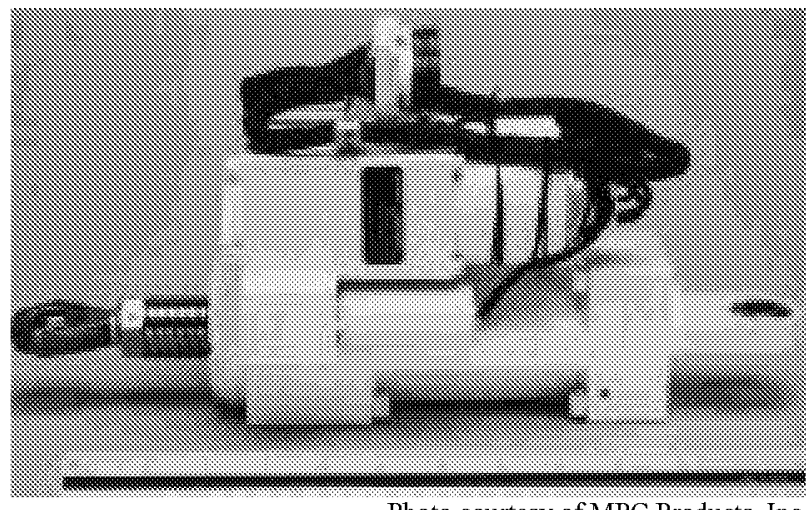

Photo courtesy of MPC Products, Inc.

Figure 5. EPAD Electromechanical actuator.

\section{Power, Control, and Monitor Electronics (PCME)}

The power, control, and monitor electronics unit was designed and built by Lockheed Martin Control Systems (Johnson City, New York). This unit combined both the low-power actuator control and monitoring functions and the highpower, high-speed motor commutation functions inside the same unit. The unit provided closedloop control of the actuator using ram position, motor velocity, and motor current. The PCME conducted fault monitoring and continuously monitored system performance. If a fault were detected, it would transition the system into a trail-damped mode, matching the behavior of the standard hydraulic actuator. It also performed both periodic built-in-test (PBIT) and initiated built-in-test (IBIT) functions.

Commutation was provided by a series of MOS-controlled thyristors (MCTs), which provided a trapezoidal torque function. Actuator power was controlled using pulse-width modulation (PWM), performed by an additional $\mathrm{MCT}$. The PCME is pictured in Figure 6.

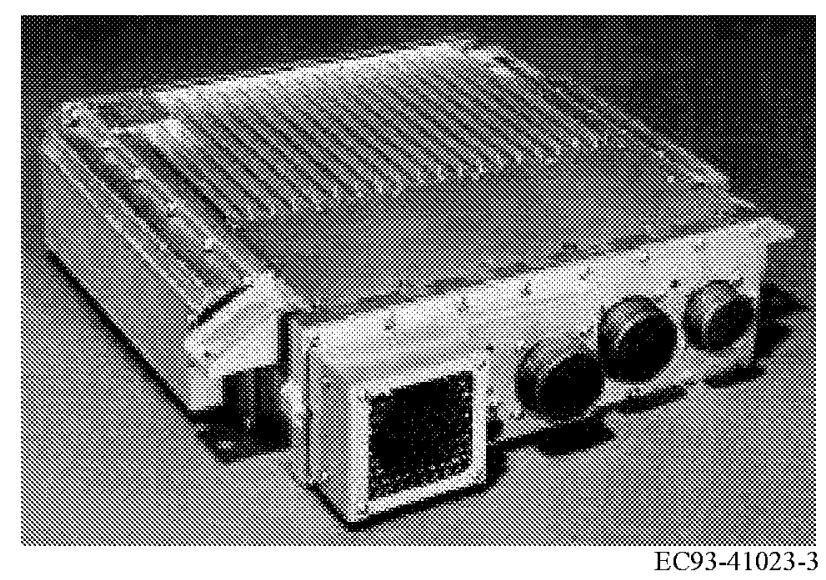

Figure 6. Power, control, and monitor electronics (PCME).

Interface Box (IBOX)

Dynamic Controls Incorporated (Dayton, Ohio) designed and built the IBOXs specifically for the EPAD program. The IBOXs served as the interface between the FCC and the PCME. They allowed the use of a research actuator on the F-18 without requiring modification of the aircraft flight control system. The IBOXs collected data from the PCME and transmitted it to the aircraft instrumentation system by means of a MIL-STD1553B [4] databus. An IBOX is pictured in Figure 7. 


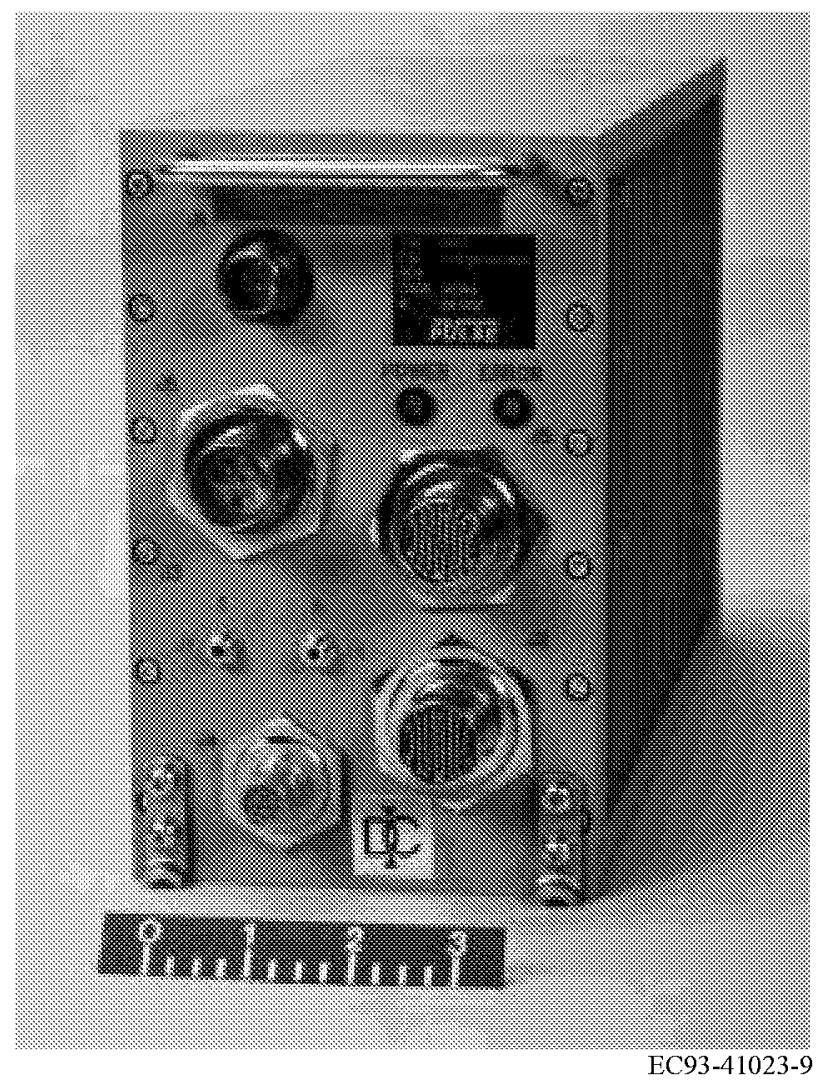

Figure 7. EPAD interface box (IBOX).

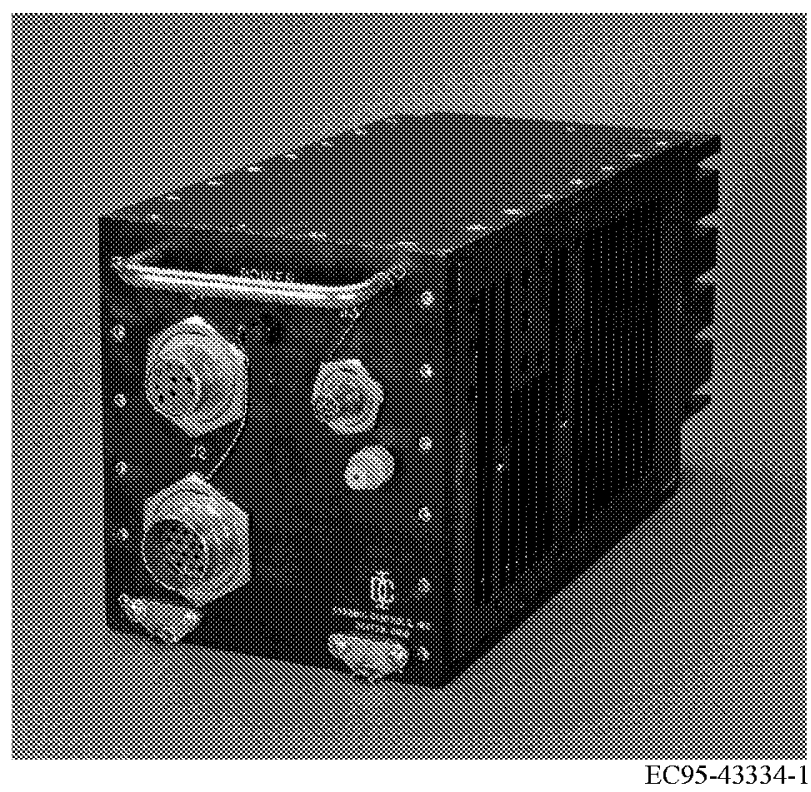

Figure 8. EPAD power conversion unit (PCU).

Power Conversion Unit (PCU)

The PCU was also developed by Dynamic Controls Incorporated, specifically for the EPAD program. It was designed to supply power to the actuator at $\pm 135 \mathrm{~V} \mathrm{dc}$, up to $100 \mathrm{~A}$. This power was produced by rectifying the 3-phase, $115 \mathrm{~V}$ ac supply produced by the aircraft generators. The PCU also served to block any regenerated power coming back from the EMA system. A PCU is pictured in Figure 8.

\section{Experiment Integration}

\section{Iron Bird Testing and Simulation}

Before the EMA system was installed on the SRA, it was first installed on a hardware-in-theloop test bench which replicated the attach points and kinematics of the left F/A-18 aileron (Figure 9). The avionics were installed on the F-18 Iron Bird (which is a retired F-18 airframe). This setup was used to perform system integration, verification, validation, and failure modes and effects testing without tying up the aircraft. In addition, several mission profiles and failure scenarios were "flown" both by engineers and pilots by connecting the Iron Bird with the Dryden F-18 simulator. This simulation proved invaluable in assessing the hazards of system failures at various points in the flight envelope, as well as generating emergency procedures.

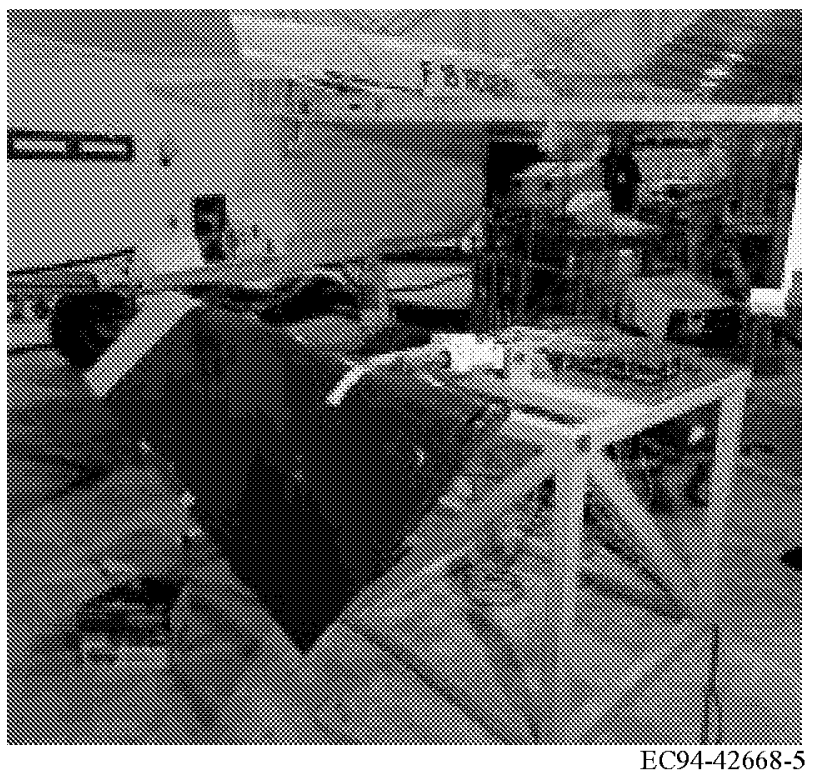

Figure 9. EPAD aileron test bench with EMA actuator installed. 


\section{Aircraft Modifications}

The SRA is an F/A-18B two-seat tactical fighter aircraft. It has been flown extensively at NASA Dryden Flight Research Center (Edwards, California) in support of aircraft systems research, including experiments in advanced actuators, air data systems, research flight controls, advanced communication links, fiber optics, and vehicle health monitoring. Several modifications were made to the SRA to accommodate the EPAD program. The left preproduction outboard wing was replaced with a modified production wing. The new wing had a "canoe" comprised of an enlarged hinge-half assembly and fairing (Figure 10). This modification was required to accommodate the larger EPAD EHA flown previously (the EMA did not require the additional space). A bank of dump resistors was mounted inside the bottom portion of this enclosure to dissipate any regenerative power produced by the EMA. A small portion of inboard wing structure was removed to make room for the installation of the PCME. The IBOXs and PCU were installed in the aircraft fuselage, in Bay 14-L. Finally, several switches were added to the front aircraft cockpit.

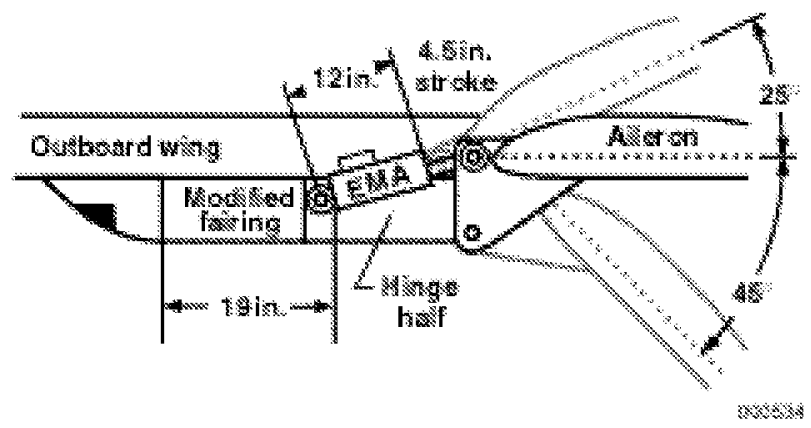

Figure 10. Actuator installation on aircraft.

\section{Integration Issues}

Several important issues surfaced during the integration of the EMA system with the SRA. The first was the location of the PCME relative to the actuator. Ideally, they would be collocated in the same bay to minimize EMI effects from the rapidly switched, high-power current flow between the PCME and motors. However, space and environmental considerations made this impossible. Locating the PCME in one of the fuselage bays would require routing the controller and actuator cabling alongside flight control wiring, greatly increasing the likelihood of electrical interference with the aircraft. The solution was to create a bay in the inboard wing section large enough to accommodate the PCME. This required some modification of the wing structure, which by conservative analysis reduced the maximum normal acceleration limit of the aircraft from $7.5 \mathrm{~g}$ to $6 \mathrm{~g}$.

Another issue that surfaced during aircraft integration was power quality. Both the PCME and IBOXs received power from a $28 \mathrm{~V}$ dc bus on the aircraft that was backed up by a battery. As a result, the assumption was made for the design of the PCME that the large bus transfer transients allowable under MIL-STD-704B (section 5.1) [5] would not occur. This proved to be incorrect in practice. While the bus was indeed battery backed, the battery was switched in with a relay only after the normal power source had completely dropped off-line. Normal switching between generators (when shutting an engine down, for example) would often cause transients on the $28 \mathrm{~V} \mathrm{dc}$ bus down to $0 \mathrm{~V}$ dc for $>30$ milliseconds. Due to the nature of the MCT switching devices employed in the PCME for motor commutation, these transients of input power could cause the MCTs to short, destroying the device. The solution was to add an external filter box to the $28 \mathrm{~V}$ dc power inputs for both the PCME and IBOXs. Once this box was installed, no further problems with power transients were observed.

One final issue of note was actuator ram rotation. The ram of the standard hydraulic actuator can rotate relative to the actuator body. The ball screw on the EMA was constrained by an antirotation device inside the actuator. Upon completion of integration testing on the Iron Bird, it was discovered that the kinematics of the aileron relative to the wing required some small amount of ram rotation during surface travel (Figure 11). This was not an issue with the hydraulic actuator, but caused excessive wear of the clevis bushings when the EMA was installed. Machining the antirotation nubs off the actuator rod end and beveling the edges of the clevis bushing solved this problem by allowing some degree of rotation between the rod end and the aileron clevis. 


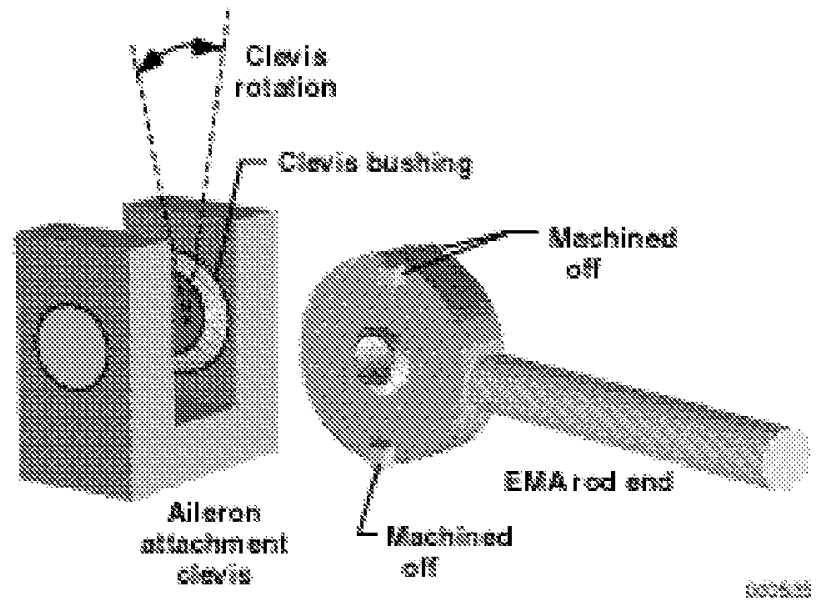

Figure 11. Aileron clevis rotation.

\section{Flight Test Results}

\section{Flight Test Summary}

The flight test program for the EPAD EMA consisted of 22 flights, for a total flight time of 25 hours, 18 minutes. The maximum altitude obtained was $43,312 \mathrm{ft}$ pressure altitude. The maximum Mach number obtained was 1.54. Maximum $\overline{\mathrm{q}}$ was $1194 \mathrm{lb} / \mathrm{ft}^{2}$. Maximum rod end load on the actuator was approximately $12,200 \mathrm{lb}$. Maximum normal acceleration was over $6 \mathrm{~g}$. Maneuvers flown included $1-\mathrm{g}$ roll doublets (both half and full stick), $1-g$ lateral stick frequency sweeps, 1-g 0-60-60-0 aileron reversals, level turns (constant $g$ and constant angle of attack), steady state high alpha flight, loaded rolls, and aerobatics. Actuator performance was judged using the standard hydraulic actuator on the right aileron as a baseline. In general, actuator performance matched that of the standard hydraulic actuator extremely well. One difference was that stall force was somewhat higher than the hydraulic actuator, and closed-loop frequency response was slightly better. This was surprising, since the open-loop frequency response testing on the ground was somewhat below that of the standard actuator. One possible explanation for this difference was the loading on the aircraft central hydraulic system caused by the combined motion of multiple surfaces during the in-flight frequency sweeps; this loading did not occur during ground testing. Since the EMA was powered by the aircraft electrical system, it was not similarly effected.

\section{EMA Performance}

Several plots of actual flight data are shown for the EPAD EMA. Figure 12 shows the position of the left and right ailerons during a full stick abrupt 0-60-60-0 aileron reversal. This maneuver was performed at Mach $0.85,40,000 \mathrm{ft}$ pressure altitude. The maximum rod end load of $4,300 \mathrm{lb}$ was recorded during this maneuver. The sign of the right surface position was inverted to simplify comparison. Note that the two surfaces track each other extremely well, with the left electric actuator actually leading the right surface by a small amount.

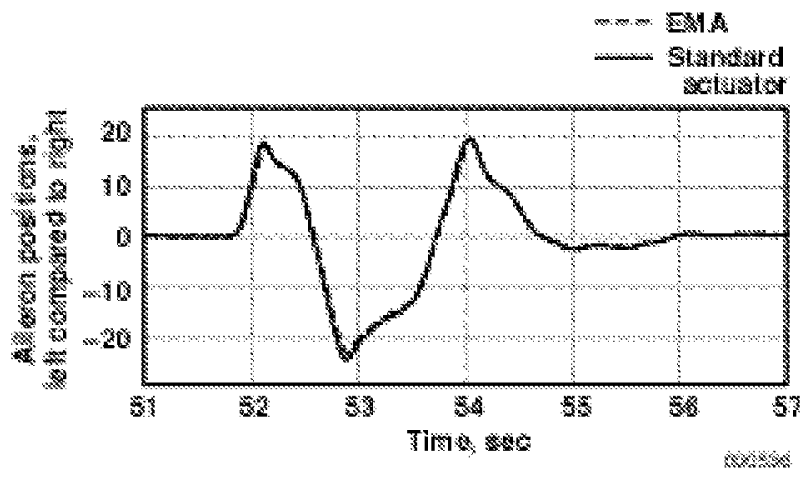

Figure 12. Full stick abrupt 0-60-60-0 aileron reversal, Mach $0.85,40,000 \mathrm{ft}$ altitude, $\bar{q}=198 \mathrm{lb} / \mathrm{ft}^{2}$.

Figure 13 shows the position of the left and right ailerons during two full stick abrupt 0-6060-0 aileron reversals, the first starting with a roll to the right and the second starting with a roll to the left. This maneuver was performed at Mach 1.2, at 35,000 ft pressure altitude. A maximum rod end load of $11,640 \mathrm{lb}$ was recorded. Again, the sign of the right surface position has been inverted for clarity. Note that the standard actuator stalls under these loading conditions, while the EMA is better able to track the command. In this case, the EMA is aided by the inertia stored in the spinning motors.

Figures 14(a) and 14(b) show the frequency response of a slow-fast lateral frequency sweep, performed at Mach 1.2, 35,000 ft pressure altitude. The maximum rod end load of $4,800 \mathrm{lb}$ was recorded. Again, note that the EMA slightly outperforms the right actuator. 


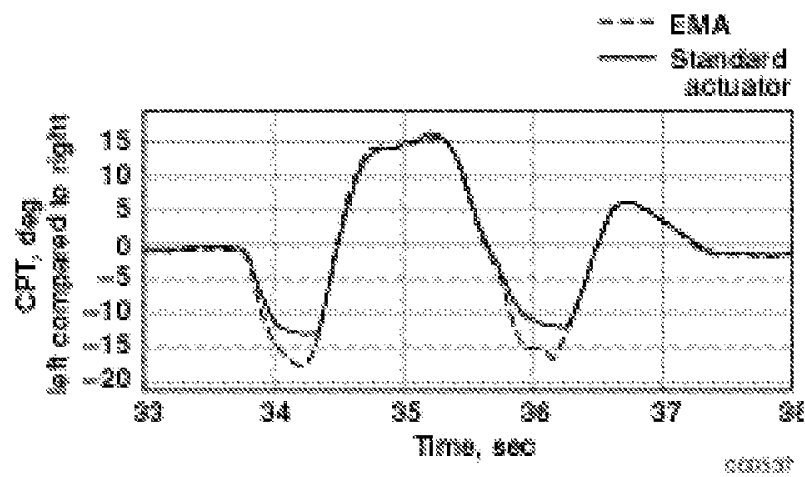

(a) Maneuver starting with roll to right, aileron reversal, right-left-right.

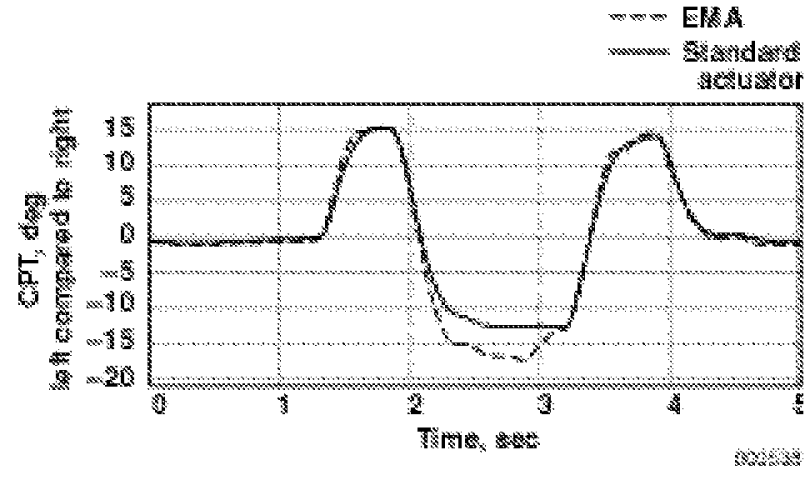

(b) Maneuver starting with roll to left., aileron reversal, left-right-left.

Figure 13. Full stick abrupt 0-60-60-0 aileron reversal, Mach $1.2,35,000 \mathrm{ft}$ altitude, $\overline{\mathrm{q}}=502 \mathrm{lb} / \mathrm{ft}^{2}$.

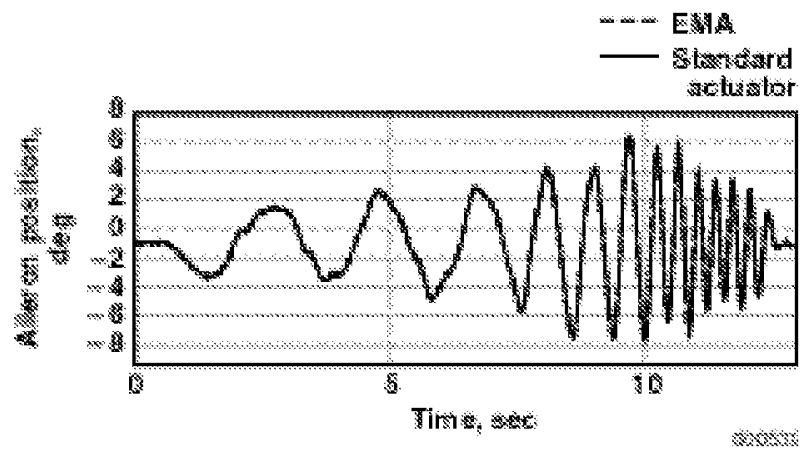

(a) The time history plot.
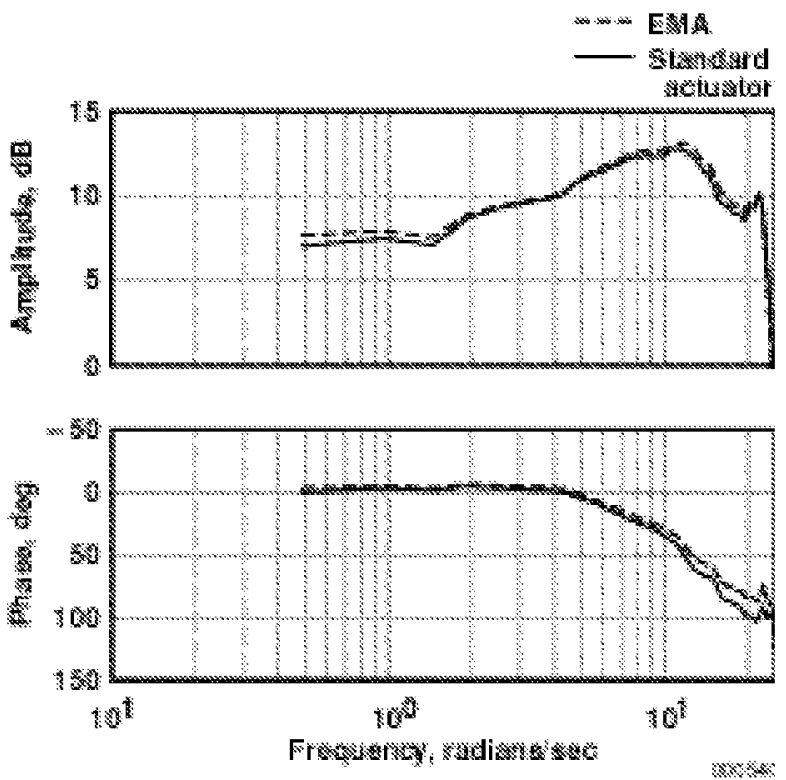

(b) The frequency response.

Figure 14. Slow-fast frequency sweep, Mach $1.2,35,000$ ft altitude, $\bar{q}=502 \mathrm{lb} / \mathrm{ft}^{2}$.

\section{Problems Uncovered}

The most significant problem uncovered during this flight test program was actuator thermal performance. This had more to do with underestimating the aircraft aileron duty cycle during the early part of the design phase than with any inherent limitations in EMA technology. The worst-case thermal loading condition was assumed to occur during hard, tactical maneuvering. In reality, the worst case occurs when the aircraft deploys the ailerons as flaps, flying around for extended periods of time with the ailerons drooped from 30 to 45 degrees. This extended operation against a steady load, coupled with the continuous small corrections commanded by the flight control system at these slow speeds, twice caused the test team to terminate a test point, raise the flaps, and allow the actuator to cool (Figure 15). MPC fabricated heat sinks for the motors to increase the conductive path to the actuator body. These were retrofitted onto the actuator midway through the flight program. This modification significantly improved actuator thermal performance. 


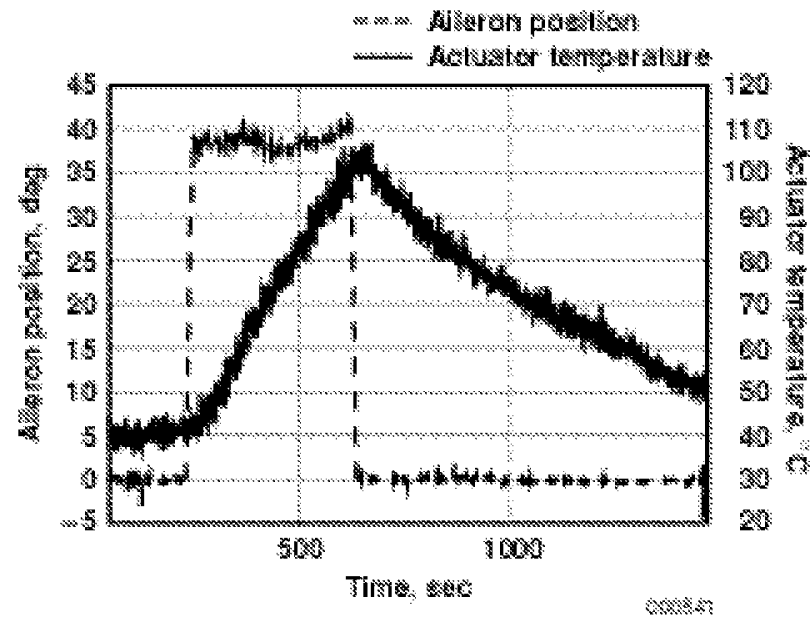

Figure 15. Actuator thermal response with flaps in full down position. Mach 0.4, $24,000 \mathrm{ft}$ altitude, $\overline{\mathrm{q}}=90 \mathrm{lb} / \mathrm{ft}^{2}$.

\section{Lessons Learned}

\section{Nonrotating Shaft}

In order for a ball screw assembly to function, rotation of the screw must be restricted. This can be done either internally with an antirotation device or externally with the actuator mounts. If done internally, one must make sure that the mounting kinematics do not assume some ram rotation capability. This is especially true when replacing hydraulic actuators with EMAs. Also, actuator installation and rigging procedures should be reviewed to ensure they are compatible with this antirotation characteristic. If the rotation is restricted externally, the additional torque loads on the actuator mount points need to be taken into consideration.

\section{Mechanical Stops}

Another difference between hydraulic and electric actuators is the implementation of mechanical stops. An EMA can store a significant amount of rotational inertia within the motors while it is moving. If the output shaft is stopped suddenly, this stored energy can damage the actuator. The EPAD EMA incorporated internal stops with some energy absorption capability, including the use of springs and slip clutches. A design requirement for the production actuator was that the actuator would be able to run into its stops at maximum rate for ten cycles without damage. The EMA failed this test early in the program, and the stops were redesigned to absorb more energy.

\section{Future Research Potential}

\section{Aircraft and Actuator Interactions}

Up until now, EMA flight demonstrations have typically focused on a single actuator. Further research could significantly increase basic knowledge on assessing the interaction between multiple electric actuators and the aircraft power system. This research could include both power usage and power regeneration issues. Power system sizing could also be addressed. Sizing the power system based on the combined maximum power draw of all the actuators leads to much larger systems than are actually required.

Research on real-world multi-actuator power use could allow sizing estimates to be more realistic. EMI with multiple electric actuators is another area lacking test result data. The adverse consequences of EMI are increasing rapidly as aircraft become more dependent on electronic systems for flight. Finally, additional research on defining the correct set of requirements and specifications for new electric actuator systems could improve development significantly. Currently, EMA systems are being designed to the same specifications as previous hydraulic actuators. The EPAD program demonstrated that this is not always correct. If a conversion scheme were developed to generate appropriate requirements for EMA actuators based on the significant amount of experience that already exists with hydraulic systems, more efficient EMAs would result.

\section{Redundancy Management Schemes}

The EPAD EMA was a single string actuator. If the system detected a failure, the actuator would transition to a safe mode. Future EMAs will have to match the redundancy of the existing hydraulic actuators they are to replace.

Implementing parallel channel redundancy is more difficult with a high-powered EMA than with less powerful systems. As the output power of an EMA increases, so do thermal and EMI radiation problems. Changes in the operating 
characteristics of individual channels resulting from thermal effects (which may not be accurately reflected in the model channel) can cause nuisance trips of the failure-detection logic. The EMI generated during high-frequency operation of an actuator can also trip the failuredetection logic or cause the actual malfunction of a channel.

\section{Summary and Remarks}

The EPAD EMA program successfully validated the use of an electric actuator on a modern, high-performance fighter aircraft. The experience gathered during this experiment has already contributed to several other programs, including the X-38 Crew Return Vehicle and the X-43A Hypersonic Scramjet Test Bed. The performance of the EPAD EMA was shown to be virtually identical to that of the standard hydraulic actuator it replaced. In fact, several pilots remarked that, except for the additional checkouts required by the research system prior to takeoff, the pilot would never have known a research actuator was on board.

The EPAD program established a methodology for testing research actuators that has proven itself effective with three different actuation systems. This includes both the system architecture and the types of tests performed. Several aspects of this test strategy are being used to flight-test the triple-redundant EMAs for the first X-38 orbital vehicle prior to its first flight.

The problems uncovered and lessons learned during the EPAD EMA program should be useful for planning to retrofit electric actuators to an existing vehicle for use in an all new design. These lessons include the effects of power transients and thermal loading, as well as design considerations such as how to implement antirotation and mechanical stops on the output shaft.

Finally, the EPAD program demonstrated the need for further research into electric actuation, including the effects of multiple PBW actuators on an aircraft and the issues involved with creating redundant $\mathrm{PBW}$ systems.

\section{Acknowledgments}

The authors would like to thank all those who made the EPAD EMA program possible. We would especially like to thank the following, whose efforts took the EPAD EMA to flight: Henry Butkiewitz, Joe Dutko, Richard Quinlivan, Binh Lee, and Bob Webb at Lockheed Martin Control Systems; Darrin Kopala, Sal Monforti, and Richard Blaschak of MPC Products; Joel Sitz and John Sharkey, the SRA Project Managers at NASA Dryden Flight Research Center; Eddie Zavala, Robert Navarro, Michael Toberman, Keith Schweikhard, Peter Urschel, John McGrath, and John Carter, the SRA Project Team at Dryden; Mark "Forger" Stuckey and Ed "Fast Eddie" Schneider, the SRA pilots; Linda Kelly and Art Lavoie for help with the F-18 Iron Bird testing; Harry Miller and Randy Glass of F-18 Avionics; and Bob Varanai, Donte Warren, and Bob Cummings, our SRA crew.

\section{References}

[1] Sitz, Joel R., F-18 Systems Research Aircraft Facility, NASA TM-4433, December 1992.

[2] Zavala, Eddie, Fiber Optic Experience with the Smart Actuation System on the F-18 Systems Research Aircraft, NASA TM-97-206223, October 1997.

[3] Navarro, Robert, Performance of an ElectroHydrostatic Actuator on the F-18 Systems Research Aircraft, NASA TM-97-206224, October 1997.

[4] Aircraft Internal Time Division Command/Response Multiplex Data Bus, MIL-STD-1553(DOD), September 8, 1986. (The current version of this standard is dated January 15, 1996.)

[5] Aircraft Electric Power Characteristics, MILSTD-704(DOD), May 1, 1991. 
Public reporting burden for this collection of information is estimated to average 1 hour per response, including the time for reviewing instructions, searching existing data sources, gathering and maintaining the data needed, and completing and reviewing the collection of information. Send comments regarding this burden estimate or any other aspect of this collection of information, including suggestions for reducing this burden, to Washington Headquarters Services, Directorate for Information Operations and Reports, 1215 Jefferson Davis Highway, Suite 1204, Arlington, VA 22202-4302, and to the Office of Management and Budget, Paperwork Reduction Project (0704-0188), Washington, DC 20503.

1. AGENCY USE ONLY (Leave blank)

2. REPORT DATE

3. REPORT TYPE AND DATES COVERED

October 2000

Conference Paper

4. TITLE AND SUBTITLE

Flight Test Experience With an Electromechanical Actuator on the F-18

Systems Research Aircraft

6. AUTHOR(S)

WU 529-61-14-E8-14-00-SRA

Stephen C. Jensen, Gavin D. Jenney, Bruce Raymond, and David Dawson

7. PERFORMING ORGANIZATION NAME(S) AND ADDRESS(ES)

NASA Dryden Flight Research Center

P.O. Box 273

Edwards, California 93523-0273

8. PERFORMING ORGANIZATION

REPORT NUMBER

$\mathrm{H}-2425$

9. SPONSORING/MONITORING AGENCY NAME(S) AND ADDRESS(ES)

10. SPONSORING/MONITORING AGENCY REPORT NUMBER

National Aeronautics and Space Administration

Washington, DC 20546-0001

H-2425

11. SUPPLEMENTARY NOTES

Presented at the 19th Digital Avionics Systems Conference, October 7-13, 2000, Philadelphia, Pennsylvania.

G. Jenney and B. Raymond, Dynamic Controls, Inc., Dayton, Ohio; D. Dawson, Wright Laboratory, WPAFB, Ohio.

12a. DISTRIBUTION/AVAILABILITY STATEMENT

12b. DISTRIBUTION CODE

Unclassified-Unlimited

Subject Category

This report is available at http://www.dfrc.nasa.gov/DTRS/

13. ABSTRACT (Maximum 200 words)

Development of reliable power-by-wire actuation systems for both aeronautical and space applications has been sought recently to eliminate hydraulic systems from aircraft and spacecraft and thus improve safety, efficiency, reliability, and maintainability. The Electrically Powered Actuation Design (EPAD) program was a joint effort between the Air Force, Navy, and NASA to develop and fly a series of actuators validating powerby-wire actuation technology on a primary flight control surface of a tactical aircraft. To achieve this goal, each of the EPAD actuators was installed in place of the standard hydraulic actuator on the left aileron of the NASA F/A-18B Systems Research Aircraft (SRA) and flown throughout the SRA flight envelope. Numerous parameters were recorded, and overall actuator performance was compared with the performance of the standard hydraulic actuator on the opposite wing. This paper discusses the integration and testing of the EPAD electromechanical actuator (EMA) on the SRA. The architecture of the EMA system is discussed, as well as its integration with the F/A-18 Flight Control System. The flight test program is described, and actuator performance is shown to be very close to that of the standard hydraulic actuator it replaced. Lessons learned during this program are presented and discussed, as well as suggestions for future research.

17. SECURITY CLASSIFICATION OF REPORT

Unclassified

NSN 7540-01-280-5500
18. SECURITY CLASSIFICATION OF THIS PAGE

Unclassified
19. SECURITY CLASSIFICATION OF ABSTRACT

Unclassified
20. LIMITATION OF ABSTRACT

Unlimited 